\title{
Fishing Clues for the Efficacy of Chemotherapy: Role of Fasting
}

\author{
Dr. C. Nithish, Dr. G. Ajith Kumar, Dr. P. Sravani \\ Department of Clinical Pharmacy, Chalmeda Ananda Rao Institute of Medical Sciences \\ \& Vaageswari College of Pharmacy, Karimnagar, Telangana, India
}

\begin{abstract}
How to cite this paper: Dr. C. Nithish | Dr. G. Ajith Kumar | Dr. P. Sravani "Fishing Clues for the Efficacy of Chemotherapy: Role of Fasting" Published in International Journal of Trend in Scientific Research and Development (ijtsrd), ISSN: 24566470, Volume-3 | Issue-4, June 2019, pp.109-111, URL: https://www.ijtsrd. com/papers/ijtsrd2

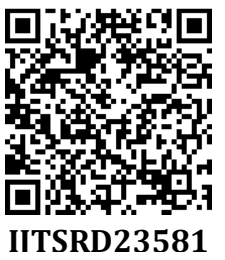
3581.pdf

Copyright (C) 2019 by author(s) and International Journal of Trend in Scientific Research and Development Journal. This is an Open Access article distributed under the terms of the Creative Commons

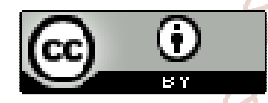
Attribution License (CC BY 4.0) (http://creativecommons.org/licenses/ by $/ 4.0$

Basic unit of human is cell. These cells divide normally but due to some disturbance in this division, leads to an abnormal growth of cells which is called as Tumor. If this tumor spreads through out the body it is called as malignancy or Cancer. Cancer, also known as a malignant tumor, is a cluster of diseases involving abnormal cell growth with the potential to spread or invade to other parts of the body[2]. Metastasis involves the spread of cancer cells from the primary tumor to surrounding tissues and to distant organs via Angiogenesis. Angiogenesis is a physiological process through which new blood vessels form from pre-existing vessels ${ }^{[3,4]}$.

Fasting is the one of oldest therapies in medicine. Many physicians throughout history and many of the oldest healing system have recommended fasting as an fundamental method of healing and prevention. Hippocrites believed that fasting enable to body heal it.

And fasting is the part of most spiritual tradition in the world and It is one of the religious practice among Christianity, Islam, Hinduism and many more ${ }^{[5]}$.

Few recent studies found that fasting can improve quality of life of the patients undergoing chemotherapy for breast and ovarian cancer. This study used a 60 hour fasting starting 36 hours before the start of chemotherapy. The results shown that participants fasting during chemotherapy reported higher tolerance to chemotherapy, few chemotherapy related side effects are decreased and higher energy levels were observed in fasted patients when compared with those who did not fast $\left[{ }^{6]}\right.$.

\section{Can Fasting cure the cancer:-}

The cure is extremely difficult for the advanced metastatic tumors if it once spread to the other organs. Major factors that trigger cancer was the dietary and lifestyle related factors, Cancers being more likely dependent on dietary habits than the other factors. There are few cancers more likely dependent on the dietary habits [7-15]. High curiosity and interest to prevent cancer by certain calorie limited diets or by fasting is raising up. Later several experiments were conducted to know, Anticancer agent tolerability and efficacy can be increased by calorie restriction ${ }^{[16-18]}$.

There was a study made by Changhan Lee et al., to know whether the fasting can increase the effectiveness of the high dose chemotherapy? So this curiosity made to do experiments on the mice. In process of experiment they injected murine breast cancer cells (4T1), melanoma cells (B16) and two neuro blastoma cell lines (NXS2 and Neuro2a) in the immune competent mice. Unfortunately it found to be true, fasting potentiated the effects of chemotherapy and prolonged the survival of mice [16]. And there is also an case study indicating that reduced side effects of the chemotherapy is seen in the cancer patients who have 
voluntarily fasted for 4 or more days along with the continuation of chemotherapy[19].

\section{Cellular fasting mechanism:}

Fasting changes the activity of many metabolic pathways. The changes in levels of metabolites translate and circulating hormones into a downfall in metabolic activity and cell division. Normal cells sensitized to chemotherapy and other cancer therapies by these starvation conditions ${ }^{[16-17]}$.

\section{Systemic changes by fasting :}

Fasting can reduce the levels of glucose, growth hormone, insulin, adrenaline, glucocorticoids. During initial post absorptive phase, which typically lasts $6-24$ hours, insulin levels start to decline, and glucagon levels rise, initiate the breakdown of glycogen stores of liver and consequent release of glucose for energy[18]. Low level of insulin and glucagon also stimulate the breakdown of triglycerides into fatty acids and glycerol. While fasting, fatty acids are utilized by the tissues for energy, while the brain relies on glucose and ketone bodies ${ }^{[12]}$. Ketone bodies helps to perform gluconeogenesis to maintain glucose levels and also it's very crucial and mostly it is utilized by brain.

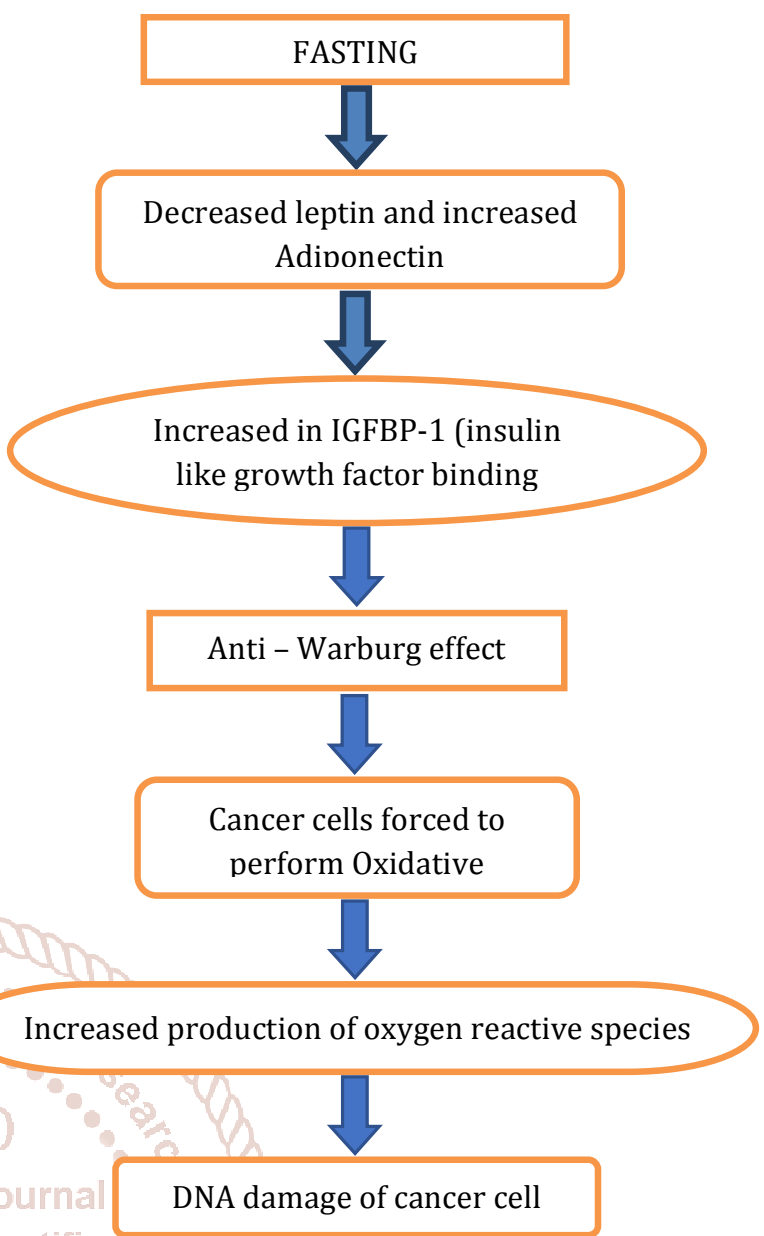

Fig-1: Summary- How fasting effects the cancer cell damage.

Types of fasting:-

Calorie Restriction :20-40\% reduction in calorie intake over along period of time (1200 caloroes for women vs 1400 calories for men per day) Intermittent Fasting :complete avoidance of calorie intake for 16-18 hours daily or alternation a fasting day with a normal energy intake day

Fasting: complete avoidance of calorie intake for anywhere from 1 day to several weeks

$>$ Intermittent Calorie Restriction:50-70\% reduction in calorie intake for short periods of time (600-1000 calories per day)

- Calorie intake less than $20 \%$ of the Total day's caloric intake is beneficial.

- Maintaining $12 \mathrm{hrs}$ starvation is more beneficial, that is entirely skipping Breakfast and make the luch be the first meal of the day ${ }^{[20]}$.

\section{Acknowledgement:}

I first would like to thank Rajan Thomas uncle, who inspired me to choose this topic. I also thank John Sunil sir, Assistant Professor, Medicinal chemistry,Vaageswari college of Pharmacy for helping me in decision making. I take pleasure to thank my team Dr. P. Sravani and Dr. G. Ajith Kumar for their tremendous efforts in making this paper.

\section{Conclusion:}

Fasting decreases the growth factors (IGF-1), insulin, glucose. Thus leads to Anti - Warburg effect. So, Cancer cells forced to perform Oxidative Phosphorylation and an Increased production of oxygen reactive species, leads to the 
DNA damage of cancer cell (specifically in response with chemotherapy).

In fasting, as tumor cells are more exposed to chemotherapy compared to that of normal cells. Chemotherapy efficacy increases on tumour cells with less Adverse drug Reactions.

On the other hand, Cancer can be prevent by fasting, as there is decrease in growth factors which contribute for the formation of tumour cells.

\section{REFERENCE}

[1] Brandhorst S, etal. Fasting and Caloric restriction in cancer prevention and treatment. Recent Results of cancer Res.2016;207:241-66.

[2] World Health Organization. Cancer Fact sheet $\mathrm{N}^{\circ} 297$. February 2014. Retrieved 10 June 2014.

[3] Seyfried, Thomas N and Leanne C Huysentruyt. "On the origin of cancer metastasis" Critical reviews in oncogenesis vol. 18,1-2 (2013): 43-73.

[4] Vahideh Keyvani; Mohammad Amin Kerachian. "The effect of fasting on the important molecular mechanisms related to cancer treatment". Journal of Nutrition, Fasting and Health, 2, 3, 2014, 113-118. doi: $10.22038 /$ jfh.2014.3510

[5] https://osher.ucsf.edu/patient-care/integrativemedicine-resources/cancer-and-nutrition/faq/cancerand-fasting-calorie-restriction.

[6] Can fasting help fight cancer : by Jamie Eske, medical news today, mon 14 jan 2019.)

[7] Lanier, A. P., Bender, T. R., Blot, W. J., Fraumeni, J. F.Jr \& Hurlburt, W. B. Cancer incidence in Alaska natives. Int J. Cancer 18, 409-412 (1976).

[8] Henderson, B. E. et al. Cancer incidence in the islands of the Pacific. Natl Cancer Inst. Monogr. 69, 73- 81 (1985).

[9] Ziegler, R. G. et al. Migration patterns and breast cancer risk in Asian-American women. J. Natl Cancer Inst. 85, 1819-1827 (1993).
[10] Le, G. M., Gomez, S. L., Clarke, C. A., Glaser, S. L. \& West, D. W. Cancer incidence patterns among Vietnamese in the United States and Ha Noi, Vietnam. Int. J. Cancer 102, 412-417 (2002).

[11] Hemminki, K. \& Li, X. Cancer risks in secondgeneration immigrants to Sweden. Int. J. Cancer 99, 229-237 (2002).

[12] Kushi, L. H. et al. American Cancer Society guidelines on nutrition and physical activity for cancer prevention: reducing the risk of cancer with healthy food choices and physical activity. CA Cancer J. Clin. 62, 30-67 (2012).

[13] Calle, E. E., Rodriguez, C., Walker-Thurmond, K. \& Thun, M. J. Overweight, obesity, and mortality from cancer in a prospectively studied cohort of U. S. adults. N. Engl. J. Med. 348, 1625-1638 (2003).

[14] Emmons, K. M. \& Colditz, G. A. Realizing the potential of cancer prevention - the role of implementation science. N. Engl. J. Med. 376, 986-990 (2017).

[15] Kerr, J., Anderson, C. \& Lippman, S. M. Physical activity, sedentary behaviour, diet, and cancer: an update and emerging new evidence. Lancet Oncol. 18, e457-e471 (2017).

[16] Lee, C. et al. Fasting cycles retard growth of tumors and sensitize a range of cancer cell types to chemotherapy. Sci. Transl Med. 4, 124ra27 (2012).

[17] Raffaghello, L. et al. Starvation-dependent differential stress resistance protects normal but not cancer cells against high-dose chemotherapy. Proc. Natl Acad. Sci. USA 105, 8215-8220 (2008).

[18] Laviano, A. \& Rossi Fanelli, F. Toxicity in chemotherapy - when less is more. N. Engl. J. Med. 366, 2319-2320 (2012).

[19] Safdie FM, Dorff T, Quinn D, Fontana L, Wei M, Lee C, Cohen P, Longo VD. Fasting and cancer treatment in humans: A case series report. Aging. 2009; 1:9881007. [PubMed: 20157582] .

[20] https://www.worldhealth.net/news/every_other_day_ fasting_may_reduce_cance/ 